\title{
Pelatihan Strategi Penulisan Proposal Penelitian Untuk Mendapat Hibah Pendanaan Dan Tatacara Mendaftar Sinta Serta Google Scholar Serta Sitasi Menggunakan Mendeley Bagi Dosen Fakultas Kedokteran Universitas Abulyatama
}

\author{
Murni $^{1}$, Amalia Effendy ${ }^{1}$, Firdaus ${ }^{1}$, Nurrahma $^{1}{ }$ Muhammad Faisal $^{1}$, Burhanuddin A.G. ${ }^{2}$ \\ ${ }^{1}$ Universitas Abulyatama, Universitas Serambi Mekkah ${ }^{2}$ \\ Email korespondensi : amel.arsitektur@gmail.com
}

\begin{abstract}
Abstrak
Sesuai dengan amanat Undang-undang No. 12 Tahun 2012 tentang Pendidikan Tinggi, disebutkan bahwa tugas Dosen adalah menjalankan Tridharma Pendidikan Tinggi. Dalam pelaksanaannya, penelitian menjadi hal yang realtif sulit untuk dilakukan oleh Dosen, hal ini terjadi karena pelaksanaan penelitian tersebut terkadang membutuhkan pendanaan yang besar. Menjawab permasalahan diatas dan meningkatkan kuantitas Proposal peneliitan yang mendapat hibah pendanaan di Lingkungan Universitas Abulyatama, maka kami para Dosen Universitas Abulyatama, melakukan kegiatan Pelatihan dengan tema : strategi strategi penulisan proposal penelitian untuk mendapat hibah pendanaan dan tatacara mendaftar sinta serta google scholar serta sitasi menggunakan mendeley bagi dosen fakultas kedokteran universitas Abulyatama. Kegiatan yang dilaksanakan pada tanggal 17 April 2021.

Kata Kunci : Pelatihan, Proposal, Hibah, Pendanaan, Sinta, Google Scholar, Mendeley
\end{abstract}

\section{PENDAHULUAN}

Sesuai dengan amanat Undang-undang No. 12 Tahun 2012 tentang Pendidikan Tinggi, disebutkan bahwa tugas Dosen adalah menjalankan Tridharma Pendidikan Tinggi. Tridharma Perguruan Tinggi yang selanjutnya disebut Tridharma adalah kewajiban Perguruan Tinggi untuk menyelenggarakan Pendidikan, penelitian, dan pengabdian kepada masyarakat (- 2012). Penelitian adalah kegiatan yang dilakukan menurut kaidah dan metode ilmiah secara sistematis untuk memperoleh informasi, data, dan keterangan yang berkaitan dengan pemahaman dan/atau pengujian suatu cabang ilmu pengetahuan dan teknologi (- 2012). Dalam pelaksanaannya, penelitian menjadi hal yang realtif sulit untuk dilakukan oleh Dosen, hal ini terjadi karena pelaksanaan penelitian tersebut terkadang membutuhkan pendanaan yang besar.

Deputi Bidang Penguatan Riset dan Pengembangan menyadari bahwa perbaikan mutu penelitian akan mampu mendorong peningkatan daya saing dan meneguhkan Kerangka Kualifikasi Nasional Indonesia (KKNI). Pemerintah Indonesia memiliki komitmen tinggi untuk meningkatkan mutu dan kuantitas publikasi akademisi. Dukungan pendanaan untuk penelitian dinyatakan secara tegas dalam Undang-Undang Nomor 12 Tahun 2012 tentang Pendidikan Tinggi Pasal 89 bahwa perguruan tinggi mendapatkan Bantuan Operasional Perguruan Tinggi Negeri (BOPTN) dimana paling sedikit 30\% dialokasikan untuk kegiatan penelitian (DRPM 2020). 
Besarnya dana penelitian yang diberikan kepada para Dosen belum berdampak signifikan terhadap kuantitas penelitian yang diusulkan ke web Simlitabmas khususnya bagi Dosen dilingkungan Universitas Abulyatama. Tahun 2021, jumlah proposal penelitian yang mendapat pendanaan dari Ristek di Universitas Abulyatama hanya 6 Proposal dengan skema Penelitian Dosen Pemula, hal ini tentunya sangat kecil jika dibandingkan dengan Kondisi pada tahun sebelumnya.

Kendala utama yang menjadi halangan bagi para Dosen unutuk mengusulkan proposal penelitian antara lain :

1. Para Dosen kesulitan untuk menemukan ide penulisan Proposal Penelitian

2. Dosen belum memiliki akun Sinta dan Google Scholar

3. Dosen belum memahami tata cara sitasi menggunakan mendeley

Untuk menjawab permasalahan diatas dan meningkatkan kuantitas Proposal peneliitan yang mendapat hibah pendanaan di Lingkungan Universitas Abulyatama, maka kami para Dosen Universitas Abulyatama, melakukan kegiatan Pelatihan dengan tema : Strategi STRATEGI PENULISAN PROPOSAL PENELITIAN UNTUK MENDAPAT HIBAH PENDANAAN dan tatacara mendaftar SINTA serta Google Scholar serta Sitasi menggunakan Mendeley bagi Dosen Fakultas Kedokteran Universitas Abulyatama. Target utama kegiatan ini adalah Dosen Fakultas Kedokteran Universitas Abulyatama, hal ini berdasarkan pertimbangan bahwa masih banyak Dosen Fakultas Kedokteran yang belum pernah mengajukan proposal Pendanaan Hibah Penelitian baik itu yang bersala dari pendanaan Ristek maupun pendanaan lainnya. Selain itu, Dosen Fakultas kedokteran tersebut memiliki potensi yang besar untuk memenangkan Hibah pendanaan Penelitian.

Kegiatan yang dilaksanakan pada awal Tahun 2021 ini, berisi tentang penjelasan tentang Strategi untuk menulis Proposal Penelitian, serta bagaimana cara mendapatkan ide untuk menulis sebuah artikel penelitian, selain itu juga dijelaskan tenatng tatacara mendapat Sinta dan Google Scholar bagi Dosen. Salah satu tujuan Sistem Nasional IPTEK adalah meningkatkan kemandirian dan daya saing bangsa yang bermakna bahwa perguruan tinggi yang didukung oleh lembaga litbang (LPNK, LPK, dan Badan Usaha) dan tenaga terampil pendidikan tinggi agar dapat memberikan kontribusi dalam penguatan perekonomian dan peningkatan kesejahteraan masyarakat (DRPM 2020). Agar amanah di atas dapat dilaksanakan dengan baik, pelaksanaan penelitian dan pengabdian kepada masyarakat di perguruan tinggi harus diarahkan untuk mencapai tujuan dan standar tertentu. Secara umum tujuan penelitian di perguruan tinggi adalah:

1. menghasilkan penelitian sesuai dengan Peraturan Menteri Pendidikan dan Kebudayaan No. 3 Tahun 2020 tentang Standar Nasional Pendidikan Tinggi;

2. menjamin pengembangan penelitian unggulan spesifik;

3. meningkatkan kapasitas penelitian;

4. mencapai dan meningkatkan mutu sesuai target dan relevansi hasil penelitian bagi masyarakat Indonesia;

5. dan meningkatkan diseminasi hasil penelitian dan perlindungan kekayaan intelektual secara nasional dan internasional.(DRPM 2020) 
Murni, dkk.

Terdapat beberapa skema hibah penelitian yang ditawarkan oleh Kementerian Riset dan Teknologi antara lain (DRPM 2020) :

A. Kategori Penelitian Kompetitif Nasional

1. Skema Penelitian Dasar (PD)

2. Skema Penelitian Terapan (PT)

3. Skema Penelitian Pengembangan (PP)

4. Skema Penelitian Dosen Pemula (PDP)

5. Skema Penelitian Kerjasama Antar Perguruan Tinggi (PKPT)

6. Skema Penelitian Pascasarjana (PPS)

B. Kategori Penelitian Desentralisasi

1. Skema Penelitian Dasar Unggulan Perguruan Tinggi (PDUPT)

2. Skema Penelitian Terapan Unggulan Perguruan Tinggi (PTUPT)

3. Skema Penelitian Pengembangan Unggulan Perguruan Tinggi (PPUPT)

C. Kategori Penelitian Penugasan

1. Skema Konsorsium Riset Unggulan Perguruan Tinggi (KRU-PT)

2. Skema Kajian Kebijakan Strategis (KKS)

3. Skema World Class Research (WCR)

4. Skema Riset Kemitraan (RK)

Target Pelatihan ini adalah Dosen Fakultas Kedokteran mengusulkan hibah dengan Skema Penelitian Dosen Pemula (PDP). Tujuan dari penelitian dosen pemula ini adalah untuk mengarahkan dan membina kemampuan meneliti dosen pemula; dan menjadi sarana latihan bagi dosen pemula untuk mempublikasikan hasil penelitiannya dalam jurnal ilmiah, baik lokal maupun nasional terakreditasi, ditujukan dosen yang belum doktor dan belum berjafa lektor kepala.(Ir and Heru 2014).

SINTA alias Science and Technology Index, Aplikasi ini berupa portal yang berisi pengukuran kinerja Ilmu Pengetahuan dan Teknologi (IPTEK) antara lain kinerja peneliti, kinerja jurnal, kinerja institusi IPTEK, dan author atau penulis jurnal. Selain mengukur kinerja IPTEK, SINTA juga menjadi alat pengindeks internasional sebagai arsip jurnal, buku, artikel, dan karya ilmiah lainnya. SINTA dikembangkan sebagai wadah hasil penelitian untuk dipublikasikan secara online.(Https://indonesia.go.id//kategori/kependudukan/1578/cara-mendaftar-sintakemenristek-untuk-publikasi-jurnal-dan-karya-ilmiah?lang=1, n.d.) Google Scholar adalah layanan pencarian khusus untuk pelajar, mahasiswa, dan akademisi yang dibuat oleh Anurag Acharya, seorang mantan akademis yang kemudian bergabung dengan tim web-indexing Google pada tahun 2000 (Https://inet.detik.com/tips-dan-trik/d-4606612/5-tips-manfaatkan-google-scholarbanyak-yang-belum-tahu, n.d.).

Mendeley adalah sebuah aplikasi reference manager berbasis free web untuk membantu dalam pembuatan refrence manager workflow (Https://www.mendeley.com/guides/desktop, n.d.). 


\section{Metode Pelaksanaan}

Kegiatan ini dilaksanakan selama 1 hari yaitu pada Haris Satu 17 April 2021, kegiatan ini diakukan secara hybrid, yaitu gabungan Antara kegiatan tatap muka dan online via aplikasi Zoom Meeting. Proses pelaksanaan kegiatan terdiri dari :

- Persiapan yaitu mempersiapkan materi pelatihan

- Melakukan pendataan jumlah peserta kegiatan yang dilakukan melalui aplikasi google form

- Mempersiapkan ruangan acara serta ruang meeting via aplikasi zoom meeting

- Pembukaan oleh Moderator dan kata Sambautan oleh Dekan Fakultas Kedokteran, dalam hal ini diwakili oleh Wakil Dekan.

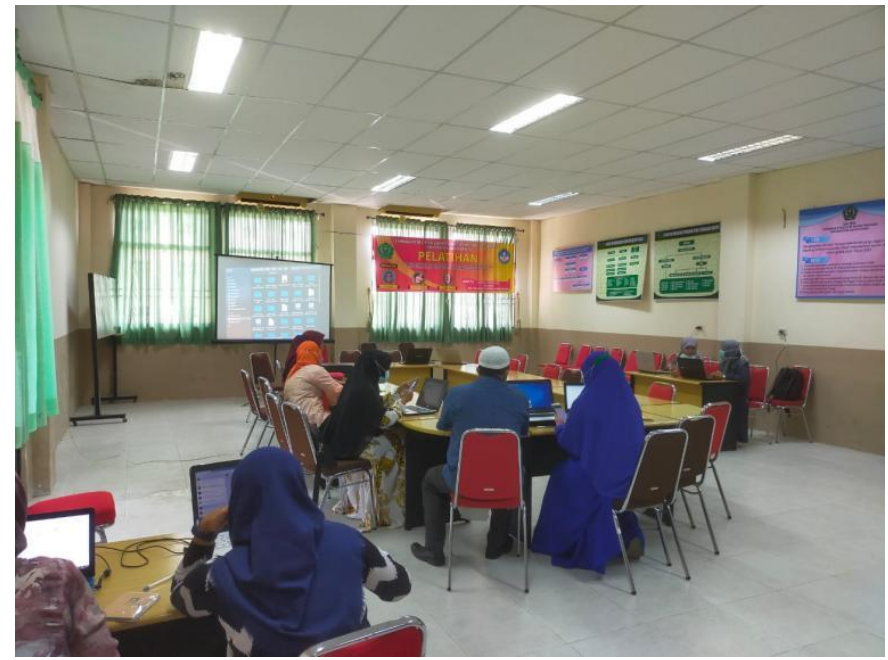

Gambar 1. Pemateri mempresentasikan materi

- Mempresentasikan Materi Strategi Penulisan Proposal agar mendapat Hibah Pendanaan

- Melakukan sesi diskusi dengan peserta pelatihan 
Murni, dkk.

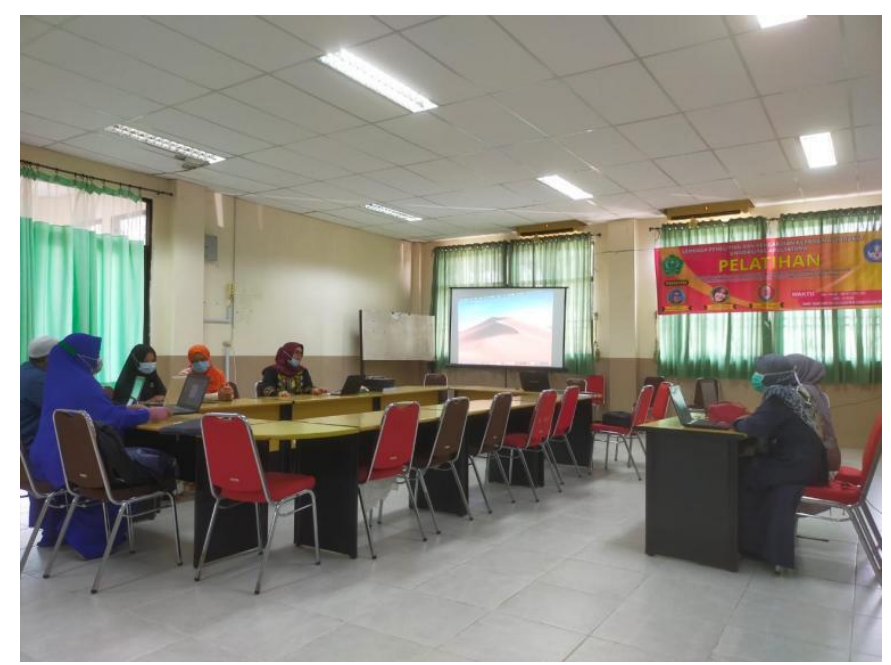

Figure 1 Sesi Diskusi

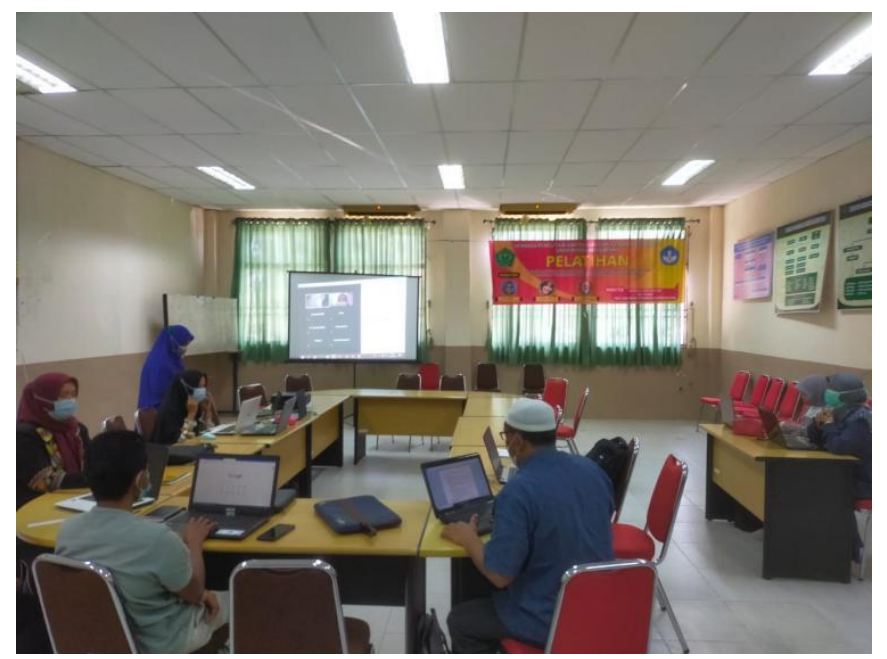

Gambar 3. Mempresentasikan Materi tata cara mendaftar sinta

- Mempresentasikan materi tata cara mendaftarSinta dan Google Scholar 


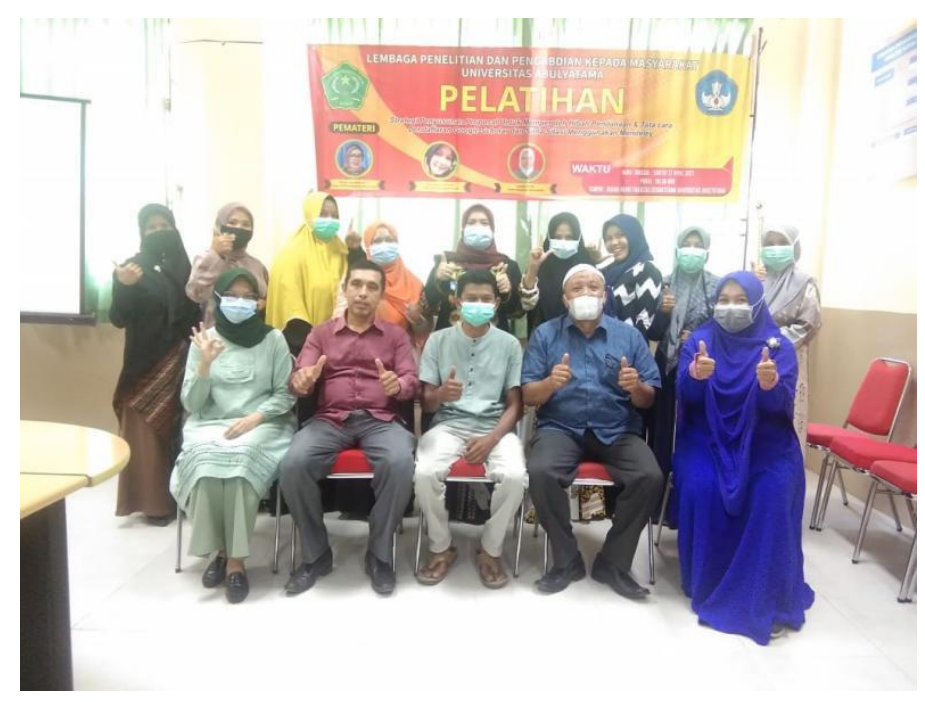

Figure 2 Foto bersama setelah acara selesai

- Praktek membuatan akun Sinta dan Google Scholar serta sesi diskusi

- Memaparkan materi Penggunaan aplikasi Mendeley

- Sesi Latihan dan diskusi

\section{HASIL DAN PEMBAHASAN}

Respon peserta Pelatihan sangat antusias terhadap kegiatan yang dilakukan ini. Setelah kegiatan ini selesai dilaksanakan, maka hasil yang diperoleh Antara lain :

1. Pelatihan Strategi penulisan Proposal penelitian agar memperoleh hibah pendanaan, setelah diberikan materi maka peserta pelatiah sangat bersemangat untuk mulai menulis proposal penelitian. Hal ini ditunjukkan dengan permintaan untuk mengadakan klinik proposal penelitian pada kegiatan selanjutnya

2. Peserta pelatihan sudah membuat akun Sinta dan Google Scholar

3. Peserta pelatihan sudah menguasai aplikasi reference manager mendeley dan akan menggunakan pada penulisan jurnal.

\section{Kesimpulan}

Dari kegiatan ini dapat disimpulkan bahwa :

1. Peserta kesulitan untuk menemukan ide menulis, setelah diberi pelatihan maka Peserta mulai mencoba untuk menulis proposal penelitian

2. Masih banyak peserta yang tidak memiliki akun Sinta dan Google Scholar, setelah diberi pelatihan maka peserta mulai membuat akun Sinta dan Google Scholar

3. Penggunaan reference manger Mendeley belum digunakan secara optimal oleh peserta, setelah dilakukan Pelatihan, maka peserta sudah mulai lancar dalam penggunaan mendeley. 
Murni, dkk.

\section{Daftar Pustaka}

-. 2012. UU No 12 Tahun 2012 Tentang Pendidikan Tinggi.

DRPM. 2020. "Panduan Penelitian Dan Pengabdian Kepada Masyarakat Buku XIII." Https://indonesia.go.id//kategori/kependudukan/1578/cara-mendaftar-sintakemenristek-untuk-publikasi-jurnal-dan-karya-ilmiah?lang=1. n.d. "Cara Mendaftar SINTA Kemenristek Untuk Publikasi Jurnal Dan Karya Ilmiah.” Https://inet.detik.com/tips-dan-trik/d-4606612/5-tips-manfaatkan-google-scholarbanyak-yang-belum-tahu. n.d. "5 Tips Manfaatkan Google Scholar, Banyak Yang Belum Tahu!"

Https://www.mendeley.com/guides/desktop. n.d. "Getting Started with Mendeley Desktop."

Ir, Prof, and Sony Heru. 2014. "Tips Umum Mengenali Skim Hibah Penelitian Dikti " Terbaru " Pengantar." 